\title{
Тенденции и способы технологизации труда в российской экономике (на примере анализа вакансий в Сибирском ФО)
}

\author{
И.Л. Сизова ${ }^{1}$, М.А. Бакаев ${ }^{2}$ \\ ${ }^{1}$ Санкт-Петербургский государственный университет, \\ ${ }^{2}$ Новосибирский государственный технический университет \\ i.sizova@spbu.ru, bakaev@corp.nstu.ru
}

\section{Аннотация}

В статье анализируются разделы актуальных вакансий, размещенных на сайтах HeadHunter, Общероссийская база вакансий («Труд всем»), Зарплата.ру и др., с локализацией в Сибирском $Ф О$, с точки зрения трудовых обязанностей и цифровых знаний и навыков, требуемых в современной экономике. Авторы приходят к следующим выводам. В настоящее время работник должен все больше учиться работать в условиях многозадачности, приобретать разнообразные навыки и знания, часто не связанные напрямую с его профессиональной подготовкой. В этом процессе, все больше трудовых задач исполняются при помощи цифровых средств, к которым относятся не только универсальные и элементарные (гаджеты, офисное ПО или социальные сети), но и специализированные: электронная коммерция, ПО управления предприятием, технологические программы и САПР, и др. В условиях широкого использования цифровой среды российскими предприятиями, современный работник должен быть готов к их освоению и перманентному обновлению.

Ключевые слова: цифровые средства труда, квалификация, профессии, рынок труда, вакансии, трудовые задачи

Библиографическая ссылка: Сизова И.Л., Бакаев М.А. Тенденции и способы технологизации труда в российской экономике (на примере анализа вакансий в Сибирском ФО) // Государство и граждане в электронной среде. Выпуск 3 (Труды XXII Международной объединенной научной конференции «Интернет и современное общество», IMS-2019, Санкт-Петербург, 19 - 22 июня 2019 г. Сборник научных трудов). - СПб: Университет ИТМО, 2019. С. 35 - 47. DOI: 10.17586/2541-979X-2019-3-35-47

\section{1. Введение}

В цифровой экономике нарастают количественные и качественные трансформации профессионального поля и трудовой деятельности. В условиях автоматизации и роботизации данная тема обсуждается в нескольких вариантах. Во-первых, ряд профессий, в основном, мало- и среднеквалифицированных, легко стандартизируются, и, соответственно, автоматизируются. Человеческий труд становится не востребованным, заменяется машинным, а существенной новизной является массовый характер устаревания профессий и предположение о том, что в первый раз способности техники (машин) превышают возможности человека [1]. Основными негативными последствиями выступают прогнозируемый рост технологической безработицы, с одной стороны, и, нехватка кадров, способных выполнять трудовые задачи по обслуживанию сложных систем, с другой. Вовторых, там, где в производство активно внедряются цифровые помощники (например, сенсорика и акторика), быстро распространяется простая и монотонная работа, уравнивающая исполнителей и приводящая к инфляции профессий и квалификаций [2]. Втретьих, распространяются неясные специализации, среди которых особенно выделяются 
т.н. «пограничные работы», предполагающие выполнение трудовых задач на разных уровнях квалификации, требующие широких компетенций и знаний $[3$, s. 253,4$]$. В этой связи выдвигаются предположения об экспансии «гранулизации» или новом способе разделения, дробления труда [5], но, в большей степени речь идет о прямо противоположном процессе - радикализованной смене структуры действий внутри профессионального поля, выражающейся, в частности, в росте и распространении все большего числа «переходов» между разными видами и формами трудовой деятельности. Для обозначения феномена в современной литературе используется понятие «гибридизация» труда [6]. Она предполагает также, что внутри организаций формируется все больше гибридных или комбинированных, смешанных профилей профессиональной деятельности (а не профессий!), которые обозначаются новым понятием «јob hopping» [7]. В их рамках реализуются новые режимы труда - вертикальное комбинирование трудовых задач, принадлежащих к одной должности, но охватывающих одновременно несколько (или много) обособленных трудовых задач, либо уровней квалификации. Всемирный банк в 2015 году предложил основываться на выявлении всех тех знаний и способностей, которые необходимы для решения современных трудовых задач. В итоге, сформировалось три уровня квалификаций в цифровой экономике: низкая (элементарные, базовые знания и навыки, как например, умение читать или писать), средняя (достаточная для выполнения рутинной работы) и высокая (профессиональные знания) [8, s. 9.].

В связи с тем, что основная масса инноваций в современности связывается с цифровизацией экономики, особенное внимание уделяется цифровым знаниям и компетенциям, необходимым для обеспечения производственных процессов. Известный социолог Э. Гидденс, в лекции 2015 г., прочитанной им в Лондонской школе экономики, назвал цифровизацию «трансформацией всего» [9]. На рынке труда, прежде всего, ощущается недостаток кадров, способных разрабатывать и внедрять высококомплексные цифровые системы, а также их обслуживать. Однако в перспективе, более фундаментальной является проблема (не)достаточности знаний и компетенций в этой области у массового работника. Частично, проблема самостийно решается за счет включения в рынок труда и занятость молодых людей, которые демонстрируют значительные успехи в области освоения и адаптации к цифровой эпохе. Так, они образует трудовой слой, который теперь называют «поколением Ү». Наличие и развитие цифровых компетенций у работников является для экономики настолько острой темой, что перерабатываются традиционные квалификационные системы с учетом цифровых знаний и навыков. Универсальный подход предполагает деление на три основные группы. Первую группу составляют поколение digital outsiders - люди, которые сопротивляются цифровым инновациям, они либо совсем не используют интернет, либо очень не уверенны в его нужности и в своих возможностях. В следующую группу включены те, которые получают цифровые знания избирательно, например, только для выполнения трудовых задач или для общения (digital immigrants). Они скептически настроены, видят в цифровых инновациях угрозы для своей безопасности или защиты персональных данных. Но для последней и самой молодой группы (digital natives), которая как раз сейчас активно вступает в трудовой возраст, цифровые знания и навыки представляют существенную часть жизни [10]. В развитии цифровых пространств они видят, скорее, новые шансы и возможности [11, s. 28-30].

Следующим важным аспектом в изучении профессиональных навыков и умений является вопрос о том, что необходимо для их модернизации в настоящее время. В исследованиях, посвященных внедрению инноваций (Science and Technology Studies (STS), Digital Sociology, Information System Research), указывается, что успех зависит от нескольких важных (и независимых друг от друга) составляющих. Особенную роль играют способности самих работников к постоянному (само)обучению и развитию. Со своей стороны, работодатели довольно радикально корректируют планы по найму работников, все чаще требуются «готовые» специалисты. Об этом свидетельствует повсеместное сокращение расходов на рабочую силу и повышение квалификации работников [12, p. 4]. 
Таким образом, работнику требуется самостоятельно ориентироваться в востребованных на рынке труда знаниях и навыках, и автономно их развивать, причем, на всем протяжении трудовой жизни. Так, стало повседневностью использование в рабочем процессе цифровых технологий, включая персональную или офисную технику, программное обеспечение, информационные и коммуникативные ресурсы и сервисы, мобильные приложения, облачные технологии и среды программирования. В настоящее время практически уже не существует организаций, которые в том или ином масштабе их не используют в трудовых и производственных процессах. Насколько данный процесс можно направить при помощи современных (и будущих) образовательных (цифровых и традиционных) систем, и насколько это устраивает самих работников, остается пока неизвестным и открытым для дальнейших обсуждений и политэкономических решений.

В самом общем виде - для успешной занятости необходимы четыре основных вида компетенций: профессиональные, коммуникативные, информационные и цифровые [13]. Прогнозы по востребованности ключевых компетенций регулярно составляются аналитиками ведущих мировых компаний и организаций (например, World Economic Forum 2015). На первом месте в 2020 году, как и в 2015 (именно тогда проводилось это исследование), по уровню востребованности останется умение решать сложные задачи (Complex Problem Solving). В целом, в современных зарубежных мониторингах занятости уже сейчас акцентируется использование интернет-технологий при выполнении трудовых задач [14], а также отмечается, что знания и компетенции, накопленный профессиональный бэкграунд работника играют решающую роль в его профессиональной карьере в условиях высокой конкуренции, свойственной цифровой экономике [15]. Немногочисленные исследования востребованных цифровых навыков у работников в России показывают, что обучение им происходит либо стихийно (за счет распространенности в повседневной жизни), либо в форме получения специализированного образования. Между тем, большинство взрослых россиян не стремится повысить требуемые на рынке труда компетенции, поскольку с ними не связан уровень их доходов. Таким образом, фиксируется отставание России от стран ОЭСР и низкий прирост в уровне овладения ключевыми компетенциями, прежде всего в области цифровой грамотности. Кроме того, указывается на отсутствие в России мониторинга компетенций взрослого населения [16]. Также можно отметить другие российские исследования [17], которые, впрочем, носят чисто обзорный характер.

Значение постоянно обновляемых умений и навыков, уровня квалификации, готовность к выполнению обязанностей в любое время и в любом месте связывается и вопросом о развитии трудового потенциала современного работника. Такой работник рассматривается как самоответственный и автономный, самостоятельно регулирующий свою деятельность и контролирующий ее результаты и уровень оплаты через выбор поступающих предложений. На этом построена одна из востребованных у работодателей концепций «использования человека в труде целиком» [18]. Это выражается как в сегментировании (разделении) рынков труда (на открытые и закрытые, первичные и вторичные), так и в разделении групп работников - на основании их базовых способностей или полученных профессиональных знаний, выражающихся, например, в большей конкурентоспособности молодых работников, мужчин на рынке труда [19, p. 3] или высокообразованных людей [19, p. 3-4], востребованности «женских» качеств в высокоаффективных и интуитивных областях деятельности [20] и т.д. Часто работодатель склонен формировать образ «идеального» работника, который в зависимости от той или иной деятельности способен проявить (и развить в себе) нужные качества. В определенном смысле подобные потребности в универсальном работнике обусловлены желанием предприятий и организаций сэкономить средства в условиях высокой конкуренции. Но, в большей степени играют роль рациональные соображения, в частности, необходимость в работниках, способных к реализации нужных задач. 
Таким образом, радикализованная смена структуры действий внутри профессионального поля (множество гибридных профилей деятельности и «переходов» внутри квалификационных уровней) и цифровая среда в рабочем процессе выступают важнейшими составляющими технологического ускорения современной экономики и успеха в рыночной конкуренции. В отличие от прогнозируемых явлений (например, утраты отдельных профессий или видов деятельности), они, являясь реальностью труда и занятости уже сегодня, формируют новые вызовы и риски для масс трудоспособных лиц. На этом основании, основной целью авторского эмпирического исследования являлось выявление основных стратегий использования работодателями трудовых ресурсов в современной российской экономике.

\section{2. Стратегии использования трудовых ресурсов в цифровую эпоху: результаты прикладного исследования вакансий с локализацией в Сибирском ФО}

Для реализации поставленной цели были собраны и содержательно проанализированы данные с сайтов вакансий: HeadHunter (hh.ru), «Труд всем» (Общероссийская база вакансий, trudvsem.ru), Зарплата.py (zarplata.ru). Для каждой из сфер, представленных в нашей программной системе мониторинга рынка труда (например, «Административный персонал», «Банки, инвестиции, лизинг», «Высший менеджмент, руководители» и т.д.), было выбрано по 15 наиболее свежих вакансий (по состоянию на конец ноября-начало декабря 2018 г.), общий объем которых составил 1359 единиц. Заданный объем выборки позволил неавтоматизированным способом обработки текста на естественном языке реализовать две основные исследовательские задачи: 1) отобрать и систематизировать видовые группы трудовых задач, и 2) соотнести их реализацию с определенными цифровыми средствами, предлагаемыми работодателем. Рассматриваемые вакансии были локализованы в Сибирском ФО (прежде всего, Новосибирской области), который характеризуется относительно высокой сложностью и наукоёмкостью экономических процессов. Содержание выборки представлено по адресу http://sai.vgroup.su/tmp/exampleVacanciesData.php (дополнительно также изучались вакансии на самих сайтах). Собранные данные изучались следующим образом.

На первом этапе отбирались и анализировались разделы вакансий, посвященные описанию трудовых задач и цифровых средств труда. Под «цифровыми средствами труда» мы понимаем использование цифрового оборудования и цифровых технологий на рабочих местах, внедренных на предприятиях и в организациях с целью выполнения определенных трудовых задач. Как показал анализ вакансий в открытых источниках (на соответствующих сайтах), работодатели все чаще размещают в объявлениях о работе подобные сведения. Цифровые средства труда были разделены по уровню сложности на три основные группы. К первой могут быть отнесены «элементарные» технологии и оборудование. Считается, что подобные средства использует все население для различных целей. Например, это могут быть разнообразные технические приспособления (компьютер, сканер, принтер, мобильный телефон), ПО (например, программа Word) и интернет (например, выход в интернет, страницы в социальных сетях, работу с электронной почтой). Ко второй группе отнесены специализированная техника и программное обеспечение, как правило, используемые в рабочих целях и создаваемые для решения определенных задач (например, бухгалтерские программы, программы управления предприятием, обработки фото и пр.). Кроме того, сюда же включены продвинутые способы использования обычных устройств и программ. Так, например, владение офисным пакетом может рассматриваться на нескольких уровнях. Большинство использует только часть возможностей таких программ как Word, Excel и др., тогда как для определенных трудовых задач (например, делопроизводства) требуются расширенные знания, то есть использование максимального количества функций программы. Наконец, к высшей группе цифровых средств труда отнесены средства, 
позволяющие развивать сами цифровые технологии и устройства. Это включает возможность программирования, выстраивание сетевого администрирования, создание систем компьютерной безопасности и т.д.

На втором этапе были проанализированы и систематизированы сами трудовые задания. В итоге сформировалась матрица, в которой трудовые задания мало зависят от названной в объявлении вакансии. В большей степени они делятся по типу деятельности и уровню квалификации, требуемому для их решения. На основе оценки требуемых квалификаций в вакансиях, авторами разработана следующая схема градации квалификаций. Она включает четыре уровня. Элементарный уровень («Без квалификации») не предполагает профессиональной подготовки и обучения работника. Предлагаемые трудовые задачи может выполнять каждый трудоспособный человек после небольшого инструктажа. Следующий уровень квалификации («Рабочая квалификация») предполагает выполнение задач, требующих профессиональных знаний и подготовки (хотя бы непродолжительной), а также сопряженных со значительной степенью физических нагрузок. Третий уровень квалификации («Средняя») является промежуточной (переходной), связанной с получением профессиональных знаний в распространенных областях деятельности, доступных для массового работника. Наконец, последний, четвертый уровень квалификации («Высшая») требует сложной профессиональной подготовки и знаний. Такая классификация имеет некоторые ограничения. Во-первых, некоторые трудовые задачи требуют непродолжительной профессиональной подготовки (специализированные курсы, мастерклассы и пр.). На этом основании они представляют собой промежуточную стадию квалификации между уровнями «Без квалификации» и «Рабочая/Средняя». Кроме того, указанные в вакансиях требования работодателя по профессиональному образованию работника не всегда соответствуют предложенному варианту. Так, указание на «в/о» без профиля или направления профессиональной подготовки, скорее всего, указывает на необходимость владения человеком общими навыками, которые в настоящее время принято называть soft skills, включающие такие, как способность обучаться, концентрация на задачах, самоответственность, коммуникабельность и пр. Хотя часть подобных навыков действительно приобретается при обучении в высшей школе, в авторской интерпретации это характеризовало деятельность на среднем уровне квалификации, так как сложная квалификации предполагала выполнение, прежде всего, специализированных видов деятельности, связанных с длительной и глубокой профессиональной подготовкой (врач, программист, инженер и пр.), тогда как владея soft skills работник способен обучится только универсальным задачам (например, проводить консультирование, переговоры, вести делопроизводство и т.д.). Все трудовые задачи, описанные в вакансиях, в процессе анализа данных, соотносились с определенных уровнем выделенных квалификаций.

На следующем этапе с каждой трудовой задачей совмещались цифровые средства труда, которые добавлялись из соответствующего раздела вакансий, если они были обозначены. Представим основные выводы.

В стратегиях использования трудовых ресурсов сильно выражена гибридизация труда. Она проявляется в том, что для одной вакансии характерно выполнение одновременно нескольких трудовых задач. Как показал анализ, чем выше от работника требуется уровень квалификации, тем больше он призван выполнять трудовых задач. Их классификации по четырем основным уровням квалификации (без квалификации; рабочая; средняя; высшая) может быть представлена следующим образом (Табл. 1).

В таблице 1 наряду в каждом уровне квалификаций сосредоточено общее число трудовых задач, востребованных в настоящее время работодателями. Второй уровень анализа в таблице 1 представляют разделенные на классы цифровые средства труда, связанные с выполнением конкретных трудовых задач, и представленные также по уровням квалификации работников. В этом случае можно сделать сразу несколько ключевых выводов. Во-первых, с усложнением квалификации работника быстро возрастает количество трудовых заданий, которые необходимо выполнять (11 трудовых задач в 
области профессиональной деятельности не требующей квалификации и 29 - в области высокой, сложной квалификации). Во-вторых, усложнение квалификации также связывается с ростом использования цифровых средств труда. Если для двух уровней низкой квалификации такие средства либо вообще не требуются, либо только незначительные, то начиная со средней квалификации востребованы уже все уровни цифровых средств труда, в том числе и сложные.

Таблица 1. Распределение трудовых задач по уровням квалификации

\begin{tabular}{|l|c|c|c|c|}
\hline \multicolumn{1}{|c|}{ Трудовые задачи } & \multicolumn{4}{|c|}{ Уровень квалификации } \\
\cline { 2 - 5 } & Без квалификации & Рабочая & Средняя & Сложная \\
\hline $\begin{array}{l}\text { Количество видов трудовых } \\
\text { задач }\end{array}$ & 11 & 11 & 21 & 29 \\
\hline \multicolumn{5}{|c|}{ Цифровые средства труда } \\
\hline Не требуются & 4 & 7 & 3 & 3 \\
Элементарные навыки и знания & 7 & 3 & 18 & 26 \\
$\begin{array}{l}\text { Специализированные навыки и } \\
\text { знания }\end{array}$ & 3 & 2 & 14 & 24 \\
Сложные навыки и знания & - & - & 3 & 11 \\
\hline
\end{tabular}

Особенная ситуация сложилась вокруг сложной профессиональной деятельности. Половина трудовых задач уже сейчас требует от работников для их выполнения владения сложными навыками и знаниями в области цифрового оборудования и технологий. В итоге можно заключить, что в настоящее время российская экономика развивается на базе значительного усложнения профессиональной деятельности. Это связывается не только с необходимостью в работниках, имеющих высокую квалификацию, но и в значительном внедрении сложных цифровых средств, при помощи которых такая работа может выполняться.

Теперь представим выделенные с описания вакансий основные блоки трудовых задач, наиболее востребованные в российских организациях и предприятиях (Табл. 2).

Представленные в таблице 2 распределенные по уровням квалификации трудовые задачи неравномерно востребованы в российской экономике. Если принять во внимание частоту их указания в вакансиях, то, прежде всего, требуются люди для решения следующих видов задач (Табл. 2). В итоге, на российском рынке труда выделяется 43 наиболее приоритетных видов деятельности, которые выполняются специалистами, претендующими на разные должности и связанные с различными уровнями квалификации. Среди задач, не требующих квалификации, наиболее необходимы люди, умеющие осуществлять сервисное обслуживание, помогать в работе более квалифицированным специалистам, осуществлять уход и патронаж, а также заниматься охраной и уборкой. В области рабочей квалификации наиболее востребованными являются задачи по техническому обслуживанию и ремонту машин, обслуживанию оборудования, коммуникаций, объектов, работе на станках, вождению спецтранспорта, работе на производстве, занятые животноводством, а также в работах по сборке, укладке, упаковке и погрузке. В области средней квалификации таких задач уже намного больше. Так, требуется уметь работать с сайтами, вести переговоры и консультировать, заниматься делопроизводством, осуществлять операционное обслуживание, работать с клиентами и заниматься продажами, и многое другое (см. Табл. 2). Для лиц, владеющих сложной квалификацией, предлагается 18 наиболее востребованных видов трудовых задач. Кроме того, часто в рамках одной должности претенденту предлагается выполнять не только ряд задач, но и задачи, относящиеся к разным уровням квалификации работников. Так, трудовые обязанности в рамках одной вакансии содержат весьма разнородную деятельность, что особенно характерно для вакансий, требующих сложную квалификацию от работника. Особенно часто работники должны уметь работать с кадрами, клиентами, заниматься аналитикой и развитием, 
организационной и административной работой, знать делопроизводство, обслуживать оборудование и коммуникации, объекты, заниматься обучением и наставничеством, вести переговоры, вникать в бухгалтерию или финансы, осуществлять продажи и учет товаров.

Такая многоликая деятельность создает условия для осуществления труда как мультизадачного, особенно, с учетом роста количества вакансий для специалистов сложной квалификации. Частично эта ситуация отображается в названиях вакансий. На современном российском рынке труда названия профессий не регламентируются, поэтому в результате сложилась зона для свободного обозначения профессий. Если работодателю требуется «многозадачный» работник, то обозначение вакансии становится во многом неясным.

Таблица 2. Трудовые задачи в контексте российской экономики

\begin{tabular}{|c|c|c|c|}
\hline \multicolumn{4}{|c|}{ Уровень квалификации } \\
\hline Без квалификации & Рабочая & Средняя & Сложная \\
\hline 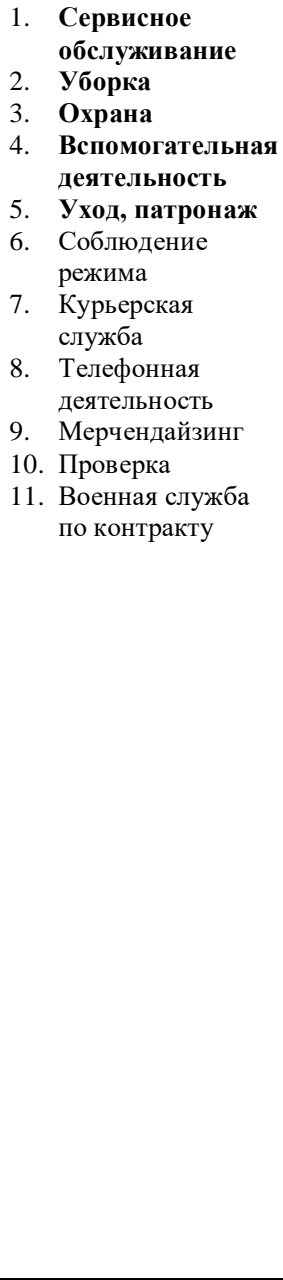 & 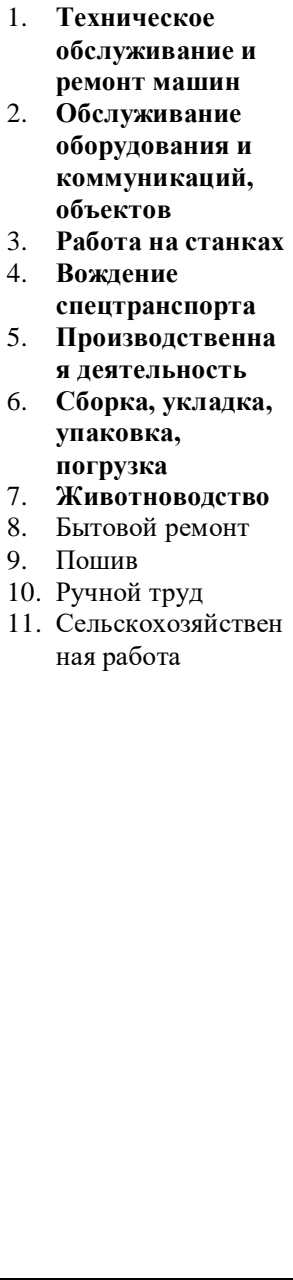 & $\begin{array}{ll}\text { 1. } & \text { Разработка, } \\
\text { продвижение и } \\
\text { дизайн сайтов } \\
\text { 2. } \text { Ведение } \\
\text { переговоров, } \\
\text { консультировани } \\
\text { е } \\
\text { 3. Делопроизводство } \\
\text { 4. } \text { Операционное } \\
\text { обслуживание } \\
\text { 5. Работа с } \\
\text { клиентами } \\
\text { 6. Продажи } \\
\text { 7. } \text { Розыскная и } \\
\text { оперативная } \\
\text { деятельность } \\
\text { 8. Развлечения } \\
\text { 9. Создание } \\
\text { рекламы } \\
\text { 10. Работа текстами и } \\
\text { графика, видео } \\
\text { 11. Приготовление } \\
\text { пищи } \\
\text { 12. Снабжение } \\
\text { 13. Складирование } \\
\text { 14. Воспитание } \\
\text { 15. Обеспечение } \\
\text { работы цифровой } \\
\text { техники } \\
\text { 16. Обеспечение } \\
\text { работы } \\
\text { направления, } \\
\text { подразделения } \\
\text { 17. Взыскание долгов } \\
\text { 18. Товароведение } \\
\text { 19. Мода и красота } \\
\text { 20. Ветеринария } \\
\text { 21. Грузооборот, } \\
\text { логистика }\end{array}$ & $\begin{array}{ll}\text { 1. } & \text { Аналитика, оценка и } \\
\text { экспертиза } \\
\text { 2. } \text { Бухгалтерия } \\
\text { 3. } \text { Консалтинг } \\
\text { 4. } \text { Обучение и } \\
\text { наставничество } \\
\text { 5. } \text { Образование } \\
\text { 6. } \text { Безопасность и } \\
\text { контроль } \\
\text { 7. } \\
\text { Охрана труда } \\
\text { 8. Пожарная охрана } \\
\text { 9. Работа с кадрами } \\
\text { 10. Финансы } \\
\text { 11. Проектная } \\
\text { деятельность } \\
\text { 12. Организационная } \\
\text { работа } \\
\text { 13. Техническая } \\
\text { деятельность } \\
\text { 14. Развитие } \\
\text { 15. Конструирование, } \\
\text { изобретение, испытания } \\
\text { 16. Закупки } \\
\text { 17. Программирование } \\
\text { 18. Юриспруденция } \\
\text { 19. Управление } \\
\text { 20. Экология } \\
\text { 21. Административная } \\
\text { деятельность } \\
\text { 22. Внедрение программных } \\
\text { продуктов } \\
\text { 23. Стартап } \\
\text { 24. Планирование } \\
\text { 25. Дизайн } \\
\text { 26. Научно- } \\
\text { исследовательская работа } \\
\text { 27. Медицинская помощь } \\
\text { 28. Создание текстов и } \\
\text { контента } \\
\text { 29. Тендерная деятельность }\end{array}$ \\
\hline
\end{tabular}

Например, представители этих «профессий» должны в рамках предлагаемой должности реализовать задачи по аналитике, оценке и экспертизе: экономист-аналитик, финансовый контролер, исполнительный директор, дизайнер-комплектатор, главный специалист, помощник оценщика и многие другие. Но «многозадачность» в настоящее время является базовой характеристикой труда. Она присутствует даже в традиционных рабочих сферах деятельности. Например, сборщик должен выполнять также работу по укладке и погрузке. 
Или сами вакансии уже задают такую направленность - сотрудник ремонтной бригадыводитель. Одной из особенностей современного рынка труда является одноименное обозначение трудовых задач, требующих знаний и навыков разного уровня (например, административная деятельность, ведение переговоров, консультирование и пр.). В итоге формируются «пограничные» деятельности в контексте квалификационных уровней (например, необходимость выполнения высококвалифицированной работы в рабочих сферах деятельности или выполнение работ средней квалификации высококвалифицированными специалистами).

Таблица 3. Цифровые средства труда

\begin{tabular}{|c|c|}
\hline $\begin{array}{l}\text { Классы цифровых } \\
\text { средств труда }\end{array}$ & Словарь \\
\hline $\begin{array}{l}\text { Знание гаджетов, } \\
\text { фурнитуры }\end{array}$ & $\begin{array}{l}\text { ПК, офисная техника, головная гарнитура, фотоаппарат, мобильные устройства } \\
\text { на базе iOS/ Android, ноутбук, принтер, сканер, планшет, навигатор }\end{array}$ \\
\hline Офисное ПО & MS Excel, MS Word, Power Point, Outlook, skype, MS Visio, MS Project, Spotlight \\
\hline $\begin{array}{l}\text { Социальные сети и } \\
\text { мессенджеры }\end{array}$ & Instagram, Facebook, VK, watsapp, viber \\
\hline $\begin{array}{l}\text { Данные, источники } \\
\text { информации }\end{array}$ & $\begin{array}{l}\text { Справочные правовые системы, электронные базы Компас, Консультант+, } \\
\text { Гарант, большие массивы данных, сводные таблицы }\end{array}$ \\
\hline Техники & Передача голосовой информации, e-mail рассылки \\
\hline Мультимедиа дизайн & $\begin{array}{l}\text { графические программы, Adobe Premier, Adobe after effect, Adobe Illustrator, } \\
\text { Adobe Flash, Adobe Lightroom, Indesign, Photoshop, CorelDraw, SVG, 3D MAX, V- } \\
\text { Ray, Corona, Sony Vegas, Sketch, Zeplin, Invision, Figma, MESA }\end{array}$ \\
\hline Игровое ПО & Action, CCG, Strategy, F2P, RPG \\
\hline Электронная коммерция & Бесконтактные технологии, переводы, е-commerce, x-Рау кошельки, SMM \\
\hline $\begin{array}{l}\text { ПО управления } \\
\text { предприятием }\end{array}$ & $\begin{array}{l}\text { 1С, MS Dynamics, AutoGRAРН, АТИ, СRМ, ЕRР, Меркурий, ЕГАИС, SAР, } \\
\text { Hyperion System, Project Expert, СБИС, Диадок, Bitrix, УРМ АС "БЮДЖЕТ", } \\
\text { Lotus Notes, Lotus Domino, АСД Союз Техноком, PerCo, Manufacturing Execution } \\
\text { System (MES), БП, УТ, ЗУП }\end{array}$ \\
\hline $\begin{array}{l}\text { Технологическое ПО и } \\
\text { САПР }\end{array}$ & $\begin{array}{l}\text { САПР «Компас-Электрик», Компас, SolidWorks, AutoCad, ArchiCAD, NanoCAD, } \\
\text { PRO100, Surpac, IIKO, ИРБИС, RadExPro, программный комплекс ЭРА, Барс, } \\
\text { Micromine (Gemcom, Datamine), Scad, ACУTП, MapInfo }\end{array}$ \\
\hline $\begin{array}{l}\text { IT, сетевое } \\
\text { администрирование }\end{array}$ & $\begin{array}{l}\text { Windows, Linux, centos, vmware, Helpdesk, ServiceDesk, SLA, ITIL/ITSM, } \\
\text { WinDBG, Sysinternals, WPP, xperf, API Monitor, IDA Pro, принципы работы } \\
\text { локальной сети, удалённое администрирование, построение локальных сетей, } \\
\text { групповые политики, доступ, служба установки/ обновления ПО, установка и } \\
\text { настройка 1C (установка, перенос баз, администрирование) }\end{array}$ \\
\hline Облачные сервисы & $\begin{array}{l}\text { Яндекс-метрика, Гугл-аналитикс, Яндекс директ, Yandex Direct, Яндекс маркет, } \\
\text { Google adwords, Bitrix }\end{array}$ \\
\hline WEB-технологии & $\begin{array}{l}\text { HTML, Websockets, CSS3, FlexBox, SEO, Joomla, Bootstrap, SASS/LESS, PHP, } \\
\text { JavaScript,.js, jQuery, Webpack, Redux, Angular, ES6+, TypeScript, Responsive Web } \\
\text { Design, Ngnix, Terraform, Stackdriver, БЭM-синтаксис, CMS, адаптивная вёрстка, } \\
\text { семантическая вёрстка, wеb и mobile пользовательские интерфейсы, работа с } \\
\text { крупным сайтами, конкурентными тематиками, высокочастотными запросами, } \\
\text { большими СЯ, ранжирование и продвижение в Яндекс и Google, выведение } \\
\text { сайтов из-под фильтров поисковых систем, }\end{array}$ \\
\hline $\begin{array}{l}\text { Прикладное и системное } \\
\text { программирование }\end{array}$ & 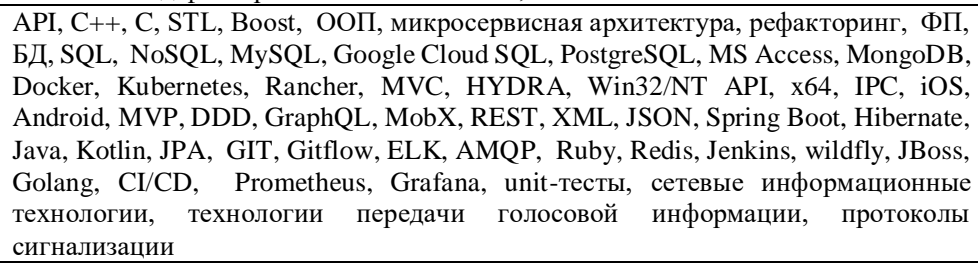 \\
\hline $\begin{array}{l}\text { Программирование } \\
\text { встраиваемых систем }\end{array}$ & $\begin{array}{l}\text { контроллеры SIMATIC, SCADA, системы WinCC и PCS7, среда TIA Portal, } \\
\text { приводная техника SIMOREG/ MICROMASTER/ SIMOVERT MASTERDRIVES/ } \\
\text { SINAMICS }\end{array}$ \\
\hline $\begin{array}{l}\text { Компьютерная } \\
\text { безопасность } \\
\end{array}$ & $\begin{array}{l}\text { АСЗИ, модели безопасности, службы, инжект, перехват функций, } \\
\text { недокументированные возможности }\end{array}$ \\
\hline
\end{tabular}


Многозадачность имеет свои ясно выраженные модификации. Для некоторых деятельностей выделяется одна главная задача, другие выступают дополнением. Для других специальностей, наоборот, выполнение нескольких трудовых задач является главной спецификой деятельности.

В таблице 3 приведены данные о необходимости привлечения цифровых средств труда для решения отдельных видов трудовых задач.

Из таблицы 3 следует, что цифровые средства труда широко распространены в профессиональной деятельности, и чем выше сложность выполняемой работы, тем больше сложных цифровых средств требуется для ее выполнения. Так, если в простых деятельностях и в сфере рабочих профессий таких средств используется мало, то уже начиная с трудовых задач, относящихся к средней квалификации, они востребованы гораздо в большей степени. При выполнении сложных задач элементарные цифровые средства уже повсеместно необходимы, но при этом в значительной степени используются специализированное и сложное оборудование и технологии. В целом, анализ цифровых средств труда, необходимых для выполнения трудовых задач в российской экономике предполагает их широкий разброс, с одной стороны, а, с другой показывает значительную сложность ведения профессиональной деятельности (Табл. 3).

Представленные в таблице 3 классы цифровых средств труда отображают все три обозначенные группы - элементарные, специализированные и сложные. Это позволяет сделать следующие выводы и предположения. Во-первых, в российской экономике задействованы все основные современные средства - оборудование и технологии. Отставание по их внедрению в трудовые процессы по сравнению с высокоразвитыми странами возможно только по отдельным направлениям профессиональной деятельности и в контексте подготовки необходимых экономике кадров. Во-вторых, в новых развивающихся сферах деятельности цифровые средства труда является неотделимым способом его реализации, причем независимо от уровня квалификации трудовых задач (например, мерчендайзер, системный администратор, дизайнер, контент-менеджер, webтехнолог, директор онлайн-школы, smm-специалист и т.д.). В-третьих, часть используемых в процессе труда цифровых средств постоянно модернизируются и требуют перманентного обновления знаний со стороны работников. Об этом свидетельствуют альтернативные варианты используемого ПО и его версий на российских предприятиях, наличие корпоративных разработок, а также вариации в сложности оборудования и технологий, используемых в труде на разных уровнях квалификации трудовых задач.

\section{Заключение}

Анализ вакансий на открытых источниках, представляющих российский рынок труда, позволяет сформулировать следующие заключительные выводы. Российская экономика воспроизводит основные черты современных рыночных экономик, в которых происходят существенные трансформационные процессы, связанные с технологическим развитием. В этих условиях, происходит смена структуры действий внутри профессионального поля. Она выражается в трех основных направлениях. Во-первых, современный труд становится многозадачным. Это требует широких навыков и компетенций от современных работников, постоянного обучения и обновления квалификаций. Во-вторых, многозадачность формирует все больше гибридных или комбинированных, смешанных профилей профессиональной деятельности и режимов труда. Среди выявленных в актуальных вакансиях доминируют связанные с одной ступенью (уровнем) квалификации, но, одновременно, нередки случаи hopping - то есть переходов между двумя или несколькими уровнями квалификации. В-третьих, существенная часть современной профессиональной деятельности выполняется при помощи цифровых средств труда (оборудования и технологий), особенно на среднем и сложном уровне квалификации, а также в распространяющихся новых видах деятельности. В российской экономике задействованы 
все основные цифровые средства труда, но уровень цифровизации еще сильно зависит от сферы трудовой деятельности и возможностей предприятий.

\section{Литература}

[1] Frey C. B., Osborne, M. A. The future of employment: how susceptible are jobs to computerisation? Oxford: Oxford University Martin Programme. 2013. [online]. URL: http://www.oxfordmartin.ox.ac.uk/downloads/academic/The_Future_of_Employment.pdf.

[2] Butollo F., Ehrlich M., Engel T. Amazonisierung der Industriearbeit? Industrie 4.0, Intralogistik und die Veränderung der Arbeitsverhältnisse in einem Montageunternehmen der Automobilindustrie //Arbeit. 2017. № 26(1). S. 33-59. DOI: 10.1515/arbeit-2017-0003.

[3] von Rottkay K. Arbeiten 4.0: Mehr Eigenverantwortung wagen / T.Sattelberger, I.Welpe, A.Boes (Hg.) Das demokratische Unternehmen. Neue Arbeits- und Führungskulturen im Zeitalter digitaler Wirtschaft. Haufe-Lexware GmbH \& Co. KG. Freiburg, 2015. S.249-262.

[4] Faßauer G., Geithner S. Entgrenzung und Grenzarbeit in Co-Konfiguration: Eine tätigkeitstheoretische Perspektive // Industrielle Beziehungen. 2016. № 23(2). S. 92-112. DOI: 10.1688/IndB-2016-02-Fassauer.

[5] Hoßfeld T., Hirth M., Tran-Gia P. Aktuelles Schlagwort: Crowdsourcing // Informatik Spektrum. 2012. № 35. S.204-208.

[6] Bögenhold D., Fachinger U. Selbstständigkeit und Entrepreneurship: Soziale Vielschichtigkeit und Forschungsfragen // Berufliche Selbstständigkeit. Springer Fachmedien. Wiesbaden, 2016. S.1-3. DOI: 10.1007/978-3-658-13283-5_1.

[7] Welskop-Defaa E.M. Erwerbsverläufe digitaler Nomaden Hybridisierung der Beschäftigungsmuster in der digitalen Transformation // A. D. Bührmann et al. (Hg.). Hybride Erwerbsformen. Springer Fachmedien. Wiesbaden, 2018. S. 107-129. DOI: 10.1007/978-3658-18982-2_5.

[8] Schoenefeld D., Hensel I., Koch J., Kocher E., Schwarz A. Jobs für die Crowds. Werkstattbericht zu einem neuen Forschungsfeld // Interdisziplinäres Forschungsprojekt: „Koordination Selbstständiger Unselbstständigkeit. Erwerbsarbeit jenseits der Organisation im Internetzeitalter“. Europa-Universität Viadrina. Viadrina Center, 2017. [online]. URL: https://www.borders-in-motion.de.

[9] Giddens A. Sociology and the Digital Revolution - the Transformation of Everything /Lecture. Department of Sociology at the London School of Economics and Political Science. 10.11.2015. URL: http://www.lse.ac.uk/Events/2015/11/20151110t1830vOT/Sociology-andthe-Digital-Revolution.

[10]Johns H. Digitalisierung der Arbeit und die Generation Y // Personal und Diversität. Schriftenreihe zur interdisziplinären Arbeitswissenschaft /A.Haunschild, G.Vedder (Hg.). Rainer Hampp Verlag, München u. Mering 2016. Band 5. S.81-91.

[11] Kaczorowski W. Die smarte Stadt - Den digitalen Wandel intelligent gestalten. Handlungsfelder Herausforderungen Strategien. Richard Boorberg Verlag. Stuttgart, 2014. S. 28-30.

[12] Stettes O. Arbeitswelt 4.0: Wohlstandszuwachs oder Ungleichheit und Arbeitsplatzverlust was bringt die Digitalisierung? //ifo Schnelldienst. 2017. № 7(70). Jahrgang 13. April 2017.

[13] Сизова И.Л., Хусяинов Т.М. Труд и занятость в цифровой экономике: проблемы российского рынка труда // Вестник СПбГУ. Социология. 2017. Т. 10, вып. 4. С. 376396. DOI: $10.21638 / 11701 /$ spbu12.2017.401.

[14]Кобяков А. Вызовы XXI века: как меняет мир четвертая промышленная революция. РБК. Опубл. 12.02.2016. http://www.rbc.ru/opinions/economics/12/02/2016/ 56bd9a4a9a79474ca8d33733.

[15] Сухомлин В.А. Открытая система ИТ-образования как инструмент формирования цифровых навыков человека // Стратегические приоритеты. 2017. № 1(11). С. 70-81. 
[16] Рылько Е.Д. Насколько компетентны сегодня взрослые россияне. // Результаты Программы международной оценки компетенций взрослых (РІААС) в РФ. М.: НИУ ВШЭ, 2015.

[17] Гимпельсон В.Е., Капелюшников Р.И., Шарунина А.В. «Дороги, которые мы выбираем»: перемещения на внешнем и внутреннем рынке труда. М.: Изд. дом ВШЭ, 2016. $48 \mathrm{c}$.

[18] Сизова И.Л., Григорьева И.А. Ломкость труда и занятости в современном мире // Социологический журнал. 2019. Т. 25, № 1. С.48-71.

[19] Autor D. Why Are There Still So Many Jobs? The History and Future of Workplace //Journal of Economic Perspectives. 2015. №29. P. 3-30.

[20]Funken Ch. Sheconomy. Warum die Arbeitswelt weiblich ist. München, 2016.

\title{
Trends and methods of labor technological advancement in Russian economy: Analysis of job offers in the Siberian Federal District
}

\author{
I. Sizova ${ }^{1}$, M. Bakaev²
}

${ }^{1}$ St. Petersburg University, ${ }^{2}$ Novosibirsk State Technical University

The article explores vacancies (job offers) published in such job-related websites as HeadHunter, All-Russian Job Base ("Work for All"), Zarplata.ru and others, with localization in the Siberian Federal District, in terms of job responsibilities and digital knowledge and skills required in a modern economy. The authors come to two main conclusions. Firstly, at the present time, an employee must increasingly learn to work in multitasking conditions, acquire a variety of skills and knowledge, often not directly related to his or her professional training. Secondly, more and more labor problems in the economy are solved with the help of certain digital objects, not only universal and elementary ones (gadgets, office software or social networks), but also specialized: electronic commerce, enterprise management software, technological programs and CAD, etc. With the current diversity and the rapid development of the digital environment, a modern employee must be constantly ready for development and renewal.

Keywords: digital means of productions, qualification, professions, labor market, vacancies, work tasks

Reference for citation: Sizova I., Bakaev M. Trends and methods of labor technological advancement in Russian economy: Analysis of job offers in the Siberian Federal District // The State and Citizens in the Electronic Environment. Vol. 3 (Proceedings of the XXII International Joint Scientific Conference «Internet and Modern Society», IMS-2019, St. Petersburg, June 19-22, 2019). - St. Petersburg: ITMO University, 2019. P. 35 - 47. DOI: 10.17586/2541-979X-2019-3$35-47$

\section{References}

[1] Frey C. B., Osborne, M. A. The future of employment: how susceptible are jobs to computerisation? Oxford: Oxford University Martin Programme. 2013. [online]. URL: http://www.oxfordmartin.ox.ac.uk/downloads/academic/The_Future_of_Employment.pdf.

[2] Butollo F., Ehrlich M., Engel T. Amazonisierung der Industriearbeit? Industrie 4.0, Intralogistik und die Veränderung der Arbeitsverhältnisse in einem Montageunternehmen der Automobilindustrie [Amazon of the industry work? Industry 4.0, intralogistics and the change of employment relationships in an assembly company of the automotive industry]. In: Arbeit [Work], 2017. № 26(1). S. 33-59. DOI: 10.1515/arbeit-2017-0003 (In German). 
[3] von Rottkay K. Arbeiten 4.0: Mehr Eigenverantwortung wagen [Working 4.0: more personal responsibility]. In: T.Sattelberger, I.Welpe, A.Boes (Hg.) Das demokratische Unternehmen. Neue Arbeits- und Führungskulturen im Zeitalter digitaler Wirtschaft [The democratic enterprise. New working and leadership cultures in the age of digital economy], HaufeLexware GmbH \& Co. KG. Freiburg, 2015. S.249-262 (In German).

[4] Faßauer G., Geithner S. Entgrenzung und Grenzarbeit in Co-Konfiguration: Eine tätigkeitstheoretische Perspektive [Demarcation and Border work in Co-configuration: a theoretical perspective]. In: Industrielle Beziehungen [Industrial Relations], 2016. № 23(2). S. 92-112. DOI: 10.1688/IndB-2016-02-Fassauer (In German).

[5] Hoßfeld T., Hirth M., Tran-Gia P. Aktuelles Schlagwort: Crowdsourcing [Current Keyword: Crowdsourcing]. In: Informatik Spektrum [Computer Science Spectrum], 2012. № 35. S.204208. (In German).

[6] Bögenhold D., Fachinger U. Selbstständigkeit und Entrepreneurship: Soziale Vielschichtigkeit und Forschungsfragen [Self-employment and Entrepreneurship: social complexity and research]. In: Berufliche Selbstständigkeit [Self-Employment], Springer Fachmedien. Wiesbaden, 2016. S.1-3. DOI: 10.1007/978-3-658-13283-5_1 (In German).

[7] Welskop-Defaa E.M. Erwerbsverläufe digitaler Nomaden Hybridisierung der Beschäftigungsmuster in der digitalen Transformation [Acquisition of digital nomads hybridization of employment patterns in digital transformation]. In: A. D. Bührmann et al. (Hg.). Hybride Erwerbsformen [Hybrid Forms of Employment], Springer Fachmedien. Wiesbaden, 2018. S. 107-129. DOI: 10.1007/978-3-658-18982-2_5 (In German).

[8] Schoenefeld D., Hensel I., Koch J., Kocher E., Schwarz A. Jobs für die Crowds. Werkstattbericht zu einem neuen Forschungsfeld [Jobs for the Crowds. Workshop report on a new field of research]. In: Interdisziplinäres Forschungsprojekt: „Koordination Selbstständiger Unselbstständigkeit. Erwerbsarbeit jenseits der Organisation im Internetzeitalter“ [Interdisciplinary Research Project: "Coordination of Independent Self-Employment. Employment beyond the organisation in the internet age"], Europa-Universität Viadrina. Viadrina Center, 2017. [online]. URL: https://www.borders-in-motion.de (In German).

[9] Giddens A. Sociology and the Digital Revolution - the Transformation of Everything /Lecture. Department of Sociology at the London School of Economics and Political Science. 10.11.2015. URL: http://www.lse.ac.uk/Events/2015/11/20151110t1830vOT/Sociology-andthe-Digital-Revolution.

[10] Johns H. Digitalisierung der Arbeit und die Generation Y [Digitisation of work and Generation Y]. In: Personal und Diversität. Schriftenreihe zur interdisziplinären Arbeitswissenschaft [Staff and diversity. Series of papers on interdisciplinary work science] /A.Haunschild, G.Vedder (Hg.). Rainer Hampp Verlag, München u. Mering 2016. Band 5. S.81-91. (In German).

[11] Kaczorowski W. Die smarte Stadt - Den digitalen Wandel intelligent gestalten. Handlungsfelder Herausforderungen Strategien [The smart city - The digital transformation of intelligent design. Fields of Action, Challenges, Strategies], Richard Boorberg Verlag. Stuttgart, 2014. (In German).

[12]Stettes O. Arbeitswelt 4.0: Wohlstandszuwachs oder Ungleichheit und Arbeitsplatzverlust was bringt die Digitalisierung? [World of work 4.0: prosperity growth or inequality and job loss-what does digitalisation mean?]. In: ifo Schnelldienst [ifo Fast service], 2017. № 7(70). Jahrgang 13. April 2017. (In German).

[13] Sizova I.L., Husyainov T.M. Trud i zanyatost' v cifrovoj ekonomike: problemy rossijskogo rynka truda [Work and employment in the digital economy: problems of the russian labour market] - Vestnik SPbGU. Sociologiya [Bulletin Of St. Petersburg State University. Sociology], 2017. Vol.10. no.4. pp. 376-396. DOI: 10.21638/11701/spbu12.2017.401. (In Russian).

[14] Kobyakov A. Vyzovy XXI veka: kak menyaet mir chetvertaya promyshlennaya revolyuciya. [Challenges of the XXI century: how the fourth industrial revolution changes the world]. - 
RBK [RBK], 12.02.2016. http:// www.rbc.ru/opinions/economics/12/02/2016/ 56bd9a4a9a79474ca8d33733 (In Russian).

[15] Suhomlin V.A. Otkrytaya sistema IT-obrazovaniya kak instrument formirovaniya cifrovyh navykov cheloveka [Open system of it education as a tool for the formation of digital skills] Strategicheskie prioritety [Strategic priority], 2017. No.1(11). pp. 70-81. (In Russian)

[16] Ryl'ko E.D. Naskol'ko kompetentny segodnya vzroslye rossiyane [How competent are adult Russians today] - Rezul'taty Programmy mezhdunarodnoj ocenki kompetencij vzroslyh (PIAAC) v RF [The results of the Programme for the international assessment of adult competencies (PIAAC) in Russia], Moscow: HSE, 2015. (In Russian).

[17] Gimpel'son V.E., Kapelyushnikov R.I., SHarunina A.V. «Dorogi, kotorye my vybiraem»: peremeshcheniya na vneshnem i vnutrennem rynke truda ["The roads we choose": movements in the external and internal labor market.]. Moscow: HSE, 2016. 48 p. (In Russian).

[18] Sizova I.L., Grigor'eva I.A. Lomkost' truda i zanyatosti v sovremennom mire [Fragility of labour and employment in the modern world] - Sociologicheskij zhurnal [Sociological journal], 2019. Vol.25, no.1, pp.48-71. (In Russian).

[19] Autor D. Why Are There Still So Many Jobs? The History and Future of Workplace //Journal of Economic Perspectives. 2015. №29. pp. 3-30.

[20] Funken Ch. Sheconomy. Warum die Arbeitswelt weiblich ist [Why the world of work is female], München, 2016. 